\title{
License to fail? How leader group prototypicality moderates the effects of leader performance on perceptions of leadership effectiveness ${ }^{2}$
}

\author{
Steffen R. Giessner ${ }^{\mathrm{a}, *}$, Daan van Knippenberg ${ }^{\mathrm{a}}$, Ed Sleebos ${ }^{\mathrm{b}}$ \\ a RSM Erasmus University, Erasmus University Rotterdam, The Netherlands \\ b Department of Public Administration and Organization Sciences, VU University Amsterdam, The Netherlands
}

\section{A R T I C L E I N F O}

\section{Keywords:}

Leader prototypicality

Leader performance

Leadership effectiveness

Trust in leadership

\begin{abstract}
A B S T R A C T
Leadership often serves as an explanatory category for performance outcomes (i.e., failure and success). This process can strengthen or weaken leadership effectiveness, because contingent on their performance leaders may gain or lose follower endorsement - the basis of leadership. Drawing on the social identity analysis of leadership, we hypothesized that leader group prototypicality and performance information interact to predict followers' perceptions of leadership effectiveness. Because group prototypical leaders are more trusted by their followers, we hypothesized that group prototypical leaders are evaluated as more effective after failure information than non-prototypical leaders. In contrast, we predicted that both prototypical and non-prototypical leaders should receive similar evaluations of leadership effectiveness after success. We found support for our predictions in a scenario experiment, a cross-sectional field study, and a laboratory experiment.
\end{abstract}

(c) 2009 Elsevier Inc. All rights reserved.

\section{Introduction}

The impact people in leadership positions have on society is undoubtedly great. The actions of leaders may determine to a large extent the performance of organizations, sports teams, and political parties, and they may even change the course of history. This has made the study of leadership an important research topic in social psychology and organizational behavior for decades (Chemers, 2001; Haslam, 2001; House \& Aditya, 1997; Reicher \& Hopkins, 2001). Because of the central position within their group, leaders are often directly associated with the performance of their team or organization (Lord, Binning, Rush, \& Thomas, 1978; Lord \& Maher, 1991; Meindl \& Ehrlich, 1987; Meindl, Ehrlich, \& Dukerich, 1985; Phillips \& Lord, 1981). Consequently, followers' perceptions of leadership effectiveness are influenced by such performance information. Followers will perceive the leader as more effective after success information and as less effective after failure information. However, anecdotal evidence suggests that sometimes a leader's effectiveness evaluation is less contingent on the actual performance of the leader. Indeed some leaders even seem to receive as much follower endorsement after failure as after success. This raises the question as to which factors affect the degree to which followers' evaluations of leadership effectiveness are contingent on actual performance information.

It is important to understand the precursors of follower evaluations and endorsement after leader performance information, because the effectiveness of a leader depends on the degree to which the leader is able to influence and motivate followers (Chemers, 2001; Yukl, 2001). Whereas former research related to the "romance of leadership" suggests that followers' leadership effectiveness evaluations are directly influenced by performance information (Lord et al., 1978; Meindl et al., 1985), we extend this theoretical perspective in the present research by incorporating principles of the social identity analysis of leadership (Haslam, 2001; Hogg, 2001; Hogg \& van Knippenberg, 2003; Turner, 1991). We argue that followers' effectiveness evaluations are influenced by performance

\footnotetext{
is The first study reported in this article was conducted during the EAESP Summer School 2002 at Marburg, Germany. We thank the social psychology department of the Phillips-University Marburg, Gemany, and the EAESP for the support in conducting Study 1, and Carien de Vries for collecting the data in Study 2.

* Corresponding author. Erasmus Research Institute of Management, Room T8-44; Burg. Oudlaan 50, P.O. Box 1738, 3000 DR Rotterdam, The Netherlands. Tel.: +31 10 4081572; fax: +31104089015

E-mail addresses: sgiessner@rsm.nl (S.R. Giessner), dknippenberg@rsm.nl (D. van Knippenberg), E.Sleebos@fsw.vu.nl (E. Sleebos).
} 
information as well as characteristics of the leader in terms of team membership. More specifically, we focus on the moderating effect of leader group prototypicality (i.e., leader's representativeness of the group identity) on the relationship between leader performance information and perceptions of leader effectiveness, proposing that leader group prototypicality prevents negative evaluations after failure. In addition, we show that an underlying process for this effect is the greater trust in leadership given to a prototypical (vs. non-prototypical) group leader. Thus, we (1) extend the "romance of leadership" perspective (i.e., followers' evaluations of leadership effectiveness after performance feedback) by highlighting the role of the shared group membership of leaders and followers, and (2) we extend the social identity analysis of leadership by including leader performance as an important influence on leadership effectiveness evaluations. In addition, we provide empirical evidence for the mediating effect of trust in leadership in enabling a group prototypical (vs. non-prototypical) leader to receive relatively high follower effectiveness evaluations after failure.

\section{Performance information and leadership endorsement}

The question of how followers' evaluations of leadership effectiveness are influenced by performance information has received strong research interest in social psychology and organizational behavior (Awamleh \& Gardner, 1999; Ensari \& Murphy, 2003; Lord \& Maher, 1991; Meindl et al., 1985; Lord et al., 1978; Shamir, 1992). Research by Lord and colleagues demonstrates that performance information related to the leader's team influenced leadership perceptions (Lord et al., 1978; Lord, Foti, \& DeVader, 1984; Phillips \& Lord, 1981; Rush, Thomas, \& Lord, 1977). They showed in a series of experimental studies that leaders of well-performing teams are evaluated as better on behaviors like initiation of structure and consideration than leaders of low-performing teams. Subsequently, Meindl and colleagues (Meindl \& Ehrlich, 1987; Meindl et al., 1985) put forward the "romance of leadership" theory to explain this attribution process. They argued that people have a romanticized, heroic view of leadership. This, in turn, leads to a kind of figureground perception of the leader compared to other possible causal factors of an event. Consequently, the leaders are accorded more influence on events than is justified and, thus, leadership serves as an explanatory category for performance of the team and organization - both organizational success and failures are often attributed to the leader. Such attributions subsequently influence followers' leadership evaluations and leadership endorsement.

Although this line of research increases our understanding of how and why follower evaluations of leadership effectiveness are affected by performance feedback, it lacks one important aspect. It fails to take into account the role of the shared group membership of the leader and followers. Participants in these studies were never asked to evaluate their own leaders, but evaluated a leader as essentially uninvolved observers. Lord and colleagues showed their participants videos of interacting groups (Lord et al., 1978; Phillips \& Lord, 1981) or provided descriptions of a leader (Rush et al., 1977). In a similar vein, Meindl and colleagues (Meindl \& Ehrlich, 1987; Meindl et al., 1985) provided descriptions of organizational performance and examined attributions to the leaders of these organizations, or they analyzed media attention to the leader when companies were performing poorly or well. Yet leaders do not only lead groups, they are also members of the groups they lead (Hollander, 1964). To put it differently, leadership processes take place in the context of a shared group membership, where leaders, as group members, ask followers, as group members, to exert themselves on behalf of the collective. Thus, follower evaluations and endorsement of a leader also depend on characteristics of the leader as a group member (Haslam, 2001; Hogg, 2001; Hogg \& van Knippenberg, 2003; Reicher \& Hopkins, 2003; van Knippenberg \& Hogg, 2003).

\subsection{Social identity analysis of leadership}

One influential approach to understanding the influence of shared group membership on perceptions, evaluations, and behavior is the social identity approach (Tajfel \& Turner, 1986; Turner, Hogg, Oakes, Reicher, \& Wetherell, 1987). The important assumption of this approach is that individuals perceive the social world in terms of social categories. The perceived membership in social categories can contribute to the self-definition of the individuals. People define themselves not only on the basis of their individual characteristics and their interpersonal relations (i.e., personal identity or personal self), but also in terms of characteristics of an ingroup to which they belong (i.e., social identity or collective self) in comparison to an outgroup. Hence, group membership can shape people's cognitions, feelings, and behavior.

Recently, the social identity approach has been used to explain leadership processes (Duck \& Fielding, 1999; Haslam \& Platow, 2001; Hogg, 2001; Hogg \& van Knippenberg, 2003; Pierro, Cicero, Bonaiuto, van Knippenberg, \& Kruglanski, 2005; Platow, Haslam, Foddy, \& Grace, 2003; Reicher \& Hopkins, 2003; van Knippenberg \& Hogg, 2003). Moreover, Haslam, Platow, Turner, Reynolds, McGarty, \& Oakes (2001; see also Haslam \& Platow, 2001) have shown that such a perspective has relevance for the "romance of leadership". They showed in an experimental study that leaders who behaviorally affirm the social identity of the group (i.e., show behavior that is in line with the norms and values of the group) receive less negative attributions after an organizational crisis than leaders who were identity-negating (i.e., show behavior that deviates from the group's values and norms). Thus, followers' negative attribution of organizational failure is moderated by the degree to which leaders show identity-affirming behavior.

The social identity analysis of leadership, however, makes not only predictions in terms of how a leader should behave, but also in terms of how a leader is generally perceived (i.e., characteristics and attributes) by the group members. A central variable in this respect is the concept of leader group prototypicality. Group prototypicality refers to the extent to which the leader is seen to embody the group identity - the group prototype (i.e., group prototypes are fuzzy sets of characteristics that in a given context define the group in comparison to relevant other groups; Hogg, 2001; Turner et al., 1987). The group prototype describes and prescribes group membership appropriate attributes in a specific context. When group membership is salient, followers' perception of the leader are contingent on the leader's group prototypicality, and followers' evaluations of the leader are affected by how similar (in terms of characteristics and attributes) the leader is to the prototype of the group. Leaders that are perceived to 
be more group prototypical are perceived to be more effective and receive stronger leadership endorsement (Hogg, 2001; Hogg \& van Knippenberg, 2003; van Knippenberg \& Hogg, 2003).

Note that this conceptualization of prototypicality has similarities and differences with the concept of prototypicality used in leader categorization theory (Lord et al., 1984; Lord \& Maher, 1991) or more recent approaches to implicit leadership theories (Epitropaki \& Martin, 2004; House, Hanges, Ruiz-Quantilla, Dorfan, Javadin \& Dickson, 1999; Offermann, Kennedy, \& Wirtz, 1994) in which leader prototypes are understood as context-specific cognitive structures or schemas reflecting the traits and behaviors of effective leaders. These schemas capture individuals' ideal-types of leadership that perceivers (e.g., followers) may use as a standard of comparison or 'benchmark' to determine their responses to and evaluations of a given leader - the more a leader matches the prototype of an effective leader, the more favorable leadership perceptions are. Just like in the social identity analyses, such prototypes are seen as mental representations of a category (i.e., the abstract category of effective leaders) and indeed both the social identity analysis of leadership and leader categorization theory have roots in the categorization-theory tradition (Lord \& Hall, 2003; van Knippenberg \& Hogg, 2003; cf. Rosch, 1978). However, the important difference is that leader categorization theory and theories of implicit leader schemas pertain to prototypes of abstract leadership categories that may vary depending on organizational contexts (e.g., military, business, etc.). The social identity analysis concerns the prototype of the group in which both leader and followers are members - the team, work group, or organization. It is also important to note that the social identity analysis and the leadership categorization tradition complement rather than contradict each other. The underlying process of leader evaluation is the same (i.e., leader fit to an abstract prototype as comparison standard), but the reference points differ. Research has shown that group prototypes become more important for leader evaluations with higher group membership salience, whereas implicit leader schemas become more important reference points of leadership evaluations with lower group membership salience (Hains, Hogg, \& Duck, 1997; Hogg, Hains, \& Mason, 1998; Platow \& van Knippenberg, 2001; Lord \& Hall, 2003). In our research, we rely on the concept of leader group prototypicality as defined in the social identity perspective.

A group prototypical as compared with a less prototypical leader is seen to better represent what defines the group and distinguishes it from other groups. Therefore, group prototypical leaders (vs. less group prototypical leaders) have more potential to influence their followers, are perceived as more effective leaders (Hains et al., 1997; Hogg, Hains, \& Mason, 1998; Platow \& van Knippenberg, 2001; Pierro et al., 2005; Platow, van Knippenberg, Haslam, van Knippenberg, \& Spears, 2006), are trusted more and seen as more charismatic (Platow et al., 2003; van Knippenberg \& van Knippenberg, 2005). These findings derive from studies using different paradigms, different operationalizations of group prototypicality, different measures of perceived leadership effectiveness, and experimental as well as field settings (for overviews see Haslam, 2001; Hogg \& van Knippenberg, 2003; van Knippenberg \& Hogg, 2003; van Knippenberg, van Knippenberg, De Cremer, \& Hogg, 2004).

\subsection{Trust in leadership and leader group prototypicality}

Recently, it has been argued that the greater trust in leadership given to a prototypical leader compared to a non-prototypical leader is an important mechanism through which group prototypical leaders receive more follower endorsement (Platow \& van Knippenberg, 2001; van Knippenberg \& Hogg, 2003; van Knippenberg \& van Knippenberg, 2005). Rousseau, Sitkin, Burt, \& Camerer (1998) defined trust as "a psychological state comprising the intention to accept vulnerability based upon positive expectations of the intentions or behavior of another" (p. 395). Dirks and Ferrin (2002) differentiated between a relationshipbased perspective and a character-based perspective in their review and meta-analysis on trust in leadership. Here, we take a character-based perspective and propose that trust in leadership is affected by leader characteristics in terms of group prototypicality, because individuals are biased in favor of their own group (Brewer, 1979; Tajfel, 1982) and such biases extend to individuals that are seen to embody the group identity. Indeed, recent research shows that trust in leadership varies depending on the leader's degree of group prototypicality (van Knippenberg \& van Knippenberg, 2005). Furthermore, the meta-analysis by Dirks and Ferrin (2002) indicates that trust in leadership has a significant impact on followers' attitudes toward the leader and the organization. In addition, trust in leadership should be an important aspect for followers because the leader typically has more power over resources and makes more important decisions on behalf of the team than other team members.

Leaders who are trusted to have the group's best interest at heart should also receive more leeway in their behaviors (Platow \& van Knippenberg, 2001; van Knippenberg \& van Knippenberg, 2005). In other words, trust in leadership should also be reflected in the allowance of more leeway for the leader's behavior or performance. This argument builds on classical research that shows that leaders who are respected and legitimate receive more normative leeway within their groups (e.g., Sherif \& Sherif, 1964). Similarly, Hollander (1964) argued that leaders who are highly normative are allowed to behave idiosyncratically and non-normatively. However, whereas Hollander assumed that these credits can only be "earned" through social exchange relationships between followers and leaders (1964; see also Hollander \& Offerman, 1990), the social identity analysis of leadership suggests that more group prototypical leaders possess more idiosyncratic credits by virtue of being representative of - embodying - the collective identity (van Knippenberg \& Hogg, 2003). In line with this, it has been shown that follower endorsement of group prototypical leaders (vs. less prototypical) is less contingent on the leaders' group-oriented behavior, such as self-sacrificing behavior (van Knippenberg \& van Knippenberg, 2005) and ingroup-favoring allocation decisions (Platow \& van Knippenberg, 2001). In contrast, a non-prototypical leader has to show more group-oriented behavior to receive follower endorsement (cf. Choi \& Mai-Dalton, 1998; De Cremer, 2002; Haslam \& Platow, 2001; Haslam et al., 2001; Platow, Hoar, Reid, Harley, \& Morrison, 1997; Platow, Reid, \& Andrew, 1998).

In sum, we argue in line with the social identity analysis of leadership that group prototypical leaders receive more trust in leadership than non-prototypical leaders. Trust in leadership implies more leeway for the leader's actions (Haslam, 2001; Hogg \& van 
Knippenberg, 2003; van Knippenberg \& Hogg, 2003). Therefore, a followers' endorsement of prototypical (vs. non-prototypical) leaders becomes less contingent on their behaviors.

\subsection{Leader group prototypicality and performance}

Applying a social identity analysis of leadership to understand followers' leadership effectiveness evaluations after performance information, we propose that leader group prototypicality moderates the influence of performance information on leadership evaluations. We expect that the greater trust given to prototypical compared to non-prototypical leaders provides the prototypical leader more leeway to deviate. Accordingly, in the case of failure to reach a performance goal, a prototypical leader should be perceived as more effective than a non-prototypical leader. In contrast, a non-prototypical leader needs to gain followers' trust. Successful performance on the part of the leader should provide the basis for this. Therefore, we predict an interaction of leader group prototypicality and leader performance on follower evaluations of leadership effectiveness. We hypothesize that the difference in follower evaluations of leadership effectiveness between a prototypical and a non-prototypical leader is stronger (i.e., higher evaluations of leadership effectiveness for group prototypical leader vs. non-prototypical leader) after leader failure than after leader success (effectiveness hypothesis). Furthermore, the greater trust in leadership given to a prototypical leader compared to a non-prototypical leader is hypothesized to mediate the effects of prototypicality on effectiveness evaluation after failure (mediation hypothesis).

Our research extends former research in three important ways. First, we extend ideas based on the "romance of leadership" theory. We argue that perceptions based on group membership (i.e., leader group prototypicality) moderate the degree to which perceptions of leadership effectiveness are affected by performance information. Second, this also extends the social identity analysis by introducing responses to leader performance as an important influence on leadership effectiveness, and by empirically testing the underlying mechanism involved in this influence. We hypothesize that trust in leadership functions as a mediator of leader group prototypicality on followers' evaluations of leadership effectiveness after failure.

\section{The current research}

Each research methodology has its own strengths and weaknesses. To provide a robust basis for our conclusion we tested our hypotheses across three studies using different methodologies. These combined experimental research, to establish causality with a high degree of internal validity, with field research, to establish generalizability to leadership in an organizational context (cf. Dipboye, 1990). In Study 1 we manipulated leader group prototypicality (prototypical vs. non-prototypical) and leader performance (success vs. failure). Study 1 was conducted within a natural group context using a scenario approach. The scenario technique allowed us to conduct an experimental study outside the laboratory with natural groups. We tested both of our hypotheses in this study. Study 2 was a cross-sectional field study with employees of a Dutch police organization. Because the original purpose of this study was based on a different theoretical issue than this paper, we were only able to test the effectiveness hypothesis in this data-set. Finally, Study 3 was conducted as a laboratory experiment using more arbitrary group memberships. As in Study 1, we manipulated leader group prototypicality and leader performance. This study allowed us to simulate a realistic group interaction instead of hypothetical scenarios as used in the first study. Additionally, in Study 3 we also looked at possible changes in perceived leader group prototypicality as a function of performance feedback, exploring the possibility that leader success or failure may affect the extent to which the leader is perceived to be group prototypical.

\subsection{Study 1}

In the first study, vignettes were used to manipulate prototypicality and performance of the leader on behalf of the group in the context of leadership of an existing (political) group, the German Green Party (i.e., Bündnis 90/Die Grünen) in the city of Marburg, Germany. We had two reasons for choosing this specific group. First, we wanted to focus on a natural group where group membership was important to its members. Second, a more pragmatic reason, was that the study was conducted in Marburg, Germany, a city known for its strong sympathy for the German Green Party (28.1\% elected the Green Party for the European elections in 2004; Mayer, 2004).

\subsubsection{Method}

3.1.1.1. Participants and design. One hundred and fifty-three participants, comprising 87 followers of the German Green Party, 60 non-followers, and 6 participants who did not indicate their affiliation took part in this study. These 66 participants were excluded from the sample because we were only interested in the sample of followers. The follower sample was aged between 19 and 75 years $(M=30.27, \mathrm{SD}=11.15)$; 39 were male, 44 were female ( 4 participants did not indicate their gender). All participants were German. The study used a two factorial between-subjects design manipulating leader group prototypicality (prototypical vs. nonprototypical) and leader performance (success vs. failure). Participants were randomly assigned to one of the four conditions of the leader prototypicality by leader performance design.

3.1.1.2. Procedure and measures. The questionnaire was titled "Questionnaire concerning the Green Future". They were handed out in the city streets, at the University of Marburg, Germany, and during a Green Party meeting in Marburg. We told potential participants that this study is about perceptions of the Green Party during the election campaign and asked them whether they would have ten minutes time to fill out a short questionnaire on this topic. 
In a short introduction, participants were informed that the questionnaire was about possible influences on perceptions of the Green Party. To gather information about this, participants were requested to try to imagine the presented scenario to the best of their ability. After the introduction, the participants were directly asked to indicate which party they supported (i.e., Green Party, Social Democrats, Communist Party, Liberal Party, Christian-Democrats, or other parties). Participants' political choice was used to differentiate between followers (supporters of the Green party) and non-followers (all other participants). If not otherwise indicated, all answers were rated on scales ranging from 1 (= totally disagree) to 7 (= totally agree).

On the next page, a short fictional vignette of a leader ${ }^{1}$ of the Green Party in Marburg was introduced as our manipulation of leader group prototypicality. The descriptions of the prototypical and non-prototypical Green Party leaders were developed in consultation with supporters of the Green Party and based on the election program of the Green Party Marburg. It can be assumed that such election programs represent, on the one hand, the core issues of the Green Party and, on the other hand, are created in a way to differentiate their own party from other parties. Therefore, it should represent what is group prototypical for the party. We used central versus peripheral issues described in this election program to create the scenarios of group prototypical versus nonprototypical leaders (i.e., the interests of the leader were based on this).

The prototypical leader was described as having studied Political Sciences, having actively participated in peace movements and Amnesty International during his study, and having a political interest in the immediate abandonment of nuclear power resources, the development of public transport, and the reduction of waste emission. The description of the non-prototypical leader was constructed in contrast to the prototypical leader. Care was taken that the non-prototypical leader could still be perceived as a possible ingroup member (i.e., supporters of the party were interviewed). The non-prototypical leader was described as having studied Engineering, having participated in two sport societies during his study, and having political interest in tax reduction of middle class employees, intensifying business relations to the states of the former Eastern block, and maintenance of the employees' wage continuation in the case of illness. Although the chairman used in the study was a fictitious person, participants were asked to imagine that this person existed in real life, and was the chairman of the Green Party in Marburg since the beginning of the year 2001.

Following the prototypicality manipulation, two items adapted from Platow and van Knippenberg (2001) measuring perceived leader group prototypicality were presented ("Overall, I would say that the chairman of the Green Party, Mr. Steinmann, represents what is characteristic about the Green Party“; "Overall, I would say that the chairman of the Green Party, Mr. Steinmann, stands for what members of the party have in common"). The average of these items served as a manipulation check of prototypicality. The next two items in the questionnaire measured trust in leadership ("I absolutely trust Mr. Steinmann."; "I think that I would give Mr. Steinmann as the chairman of our Green Party a lot of leeway."). The average of these two items was used in further analyses. We measured trust in leadership before the leader performance manipulation because we predicted that trust in leadership would serve as a buffer in the case of leader failure. This point of measurement also ensured that we were able to test the causal link as hypothesized.

On the next page, participants continued with the second part of the scenario - the manipulation of leader performance. It was described that a major chemical company planned to build a factory in the district where the party was elected. The leader of the Green Party and other political leaders were involved in a negotiation about the use of financial state subsidies, which could be invested in either an ecological construction of the factory or in a new highway connection to the planned chemical factory. The main interest of the Green Party was the ecological construction of the factory and it was described that the decision of the negotiation could have an impact on the next election. Participants randomly received a description of the outcome of the negotiation that was in favor of the ecological construction (i.e., success condition) or in favor of the highway connection (i.e., failure condition).

Following the performance manipulation, we included nine items adapted from different studies (Platow et al., 1997; Haslam et al., 2001) to measure perceived leadership effectiveness (e.g., "If an election will take place, I would vote for Mr. Steinmann to become the chairman."; "I think that Reiner Steinmann acted completely like a leader."; "In general, Reiner Steinmann is a good leader for the Green Party."). A principal component analysis conducted with these items revealed only one strong general factor that explained $63 \%$ of the variance. Therefore, we created a measure of leadership effectiveness by averaging the nine items (see Table 1 for means, standard deviations, and correlations of all measures).

Subsequently, participants were asked to indicate whether the leader performance was successful or not successful. This item served as a manipulation check of our performance manipulation. All participants indicated the intended outcome. Finally, participants were asked to answer some demographic questions.

\subsubsection{Results ${ }^{2}$}

3.1.2.1. Leader group prototypicality. In order to test whether the manipulation of prototypicality had the expected effect on perceived prototypicality, an independent samples $t$-test was performed. The analysis yielded a significant effect of the leader group prototypicality manipulation, $t(83)=7.05, p<.001$. The prototypical leader was perceived as more prototypical $(M=4.18$, $\mathrm{SD}=1.14)$ than the non-prototypical leader $(M=3.17, \mathrm{SD}=1.01)$, as was intended by the manipulation.

\footnotetext{
${ }^{1}$ We chose a male leader for this study, because the actual leader of the Green Party in Marburg was a male leader at the time we conducted this study. We, however, do not assume any gender effect of the leader for our study.

${ }^{2}$ Differences in the degrees of freedom are explained by missing values in the questionnaire. The results of the analyses do not substantially change when leaving the cases with missing values out of the analysis.
} 
Table 1

Means, standard deviations, Cronbach's alpha (in correlation matrix diagonal) and correlations of the manipulation check of leader prototypicality, trust in leadership, and leadership effectiveness in Study 1.

\begin{tabular}{lllll}
\hline & $M$ & $S D$ & $(1)$ & $(3)$ \\
\hline (1) Leader prototypicality & 3.94 & 1.35 & $(.80)$ & $.43^{* *}(.54)$ \\
(2) Trust in leadership & 3.60 & 1.25 & $.34^{*}(.41)$ & $(.80)$ \\
(3) Leadership effectiveness & 4.26 & 1.21 & $.31^{*}(.53)$ & $(.93)$ \\
\hline
\end{tabular}

$* p<.01 * * p<.001$

The correlations not within brackets are partial correlations which have the effect of our manipulations and their interaction removed, whereas the correlations within brackets represent the zero-order correlations.

3.1.2.2. Trust in leadership. An independent sample $t$-test on trust in leadership yielded a significant effect of the leader group prototypicality manipulation, $t(81)=3.48, p=.001$. In line with our hypothesis, the participants indicated more trust in the prototypical leader $(M=4.08, \mathrm{SD}=1.18)$ than in the non-prototypical leader $(M=3.18, \mathrm{SD}=1.16)$.

3.1.2.3. Leadership effectiveness ${ }^{3}$. To test our effectiveness hypothesis, a 2 (leader group prototypicality) $\times 2$ (leader performance) between-subjects ANOVA was performed on perceived leadership effectiveness. The analysis yielded a main effect of leader group prototypicality, $F(1,81)=8.33, p<.01, \eta_{\mathrm{p}}^{2}=.09$, and a significant main effect of leader performance, $F(1,81)=21.06, p<.01, \eta_{\mathrm{p}}^{2}=.21$. These main effects were, however, qualified by the predicted two-way interaction, $F(1,81)=4.49, p=.04, \eta_{\mathrm{p}}^{2}=.05$. The pattern of results (see Fig. 1) supported our effectiveness hypothesis. That is, participants in the non-prototypical leader/failure condition perceived their leader as less effective than the participants in the other three conditions. Additional simple main effect analyses within the success condition yielded no significant effect of leader group prototypicality on perceived leadership effectiveness, $F(1,81)=.35$, $p=.55, \eta_{\mathrm{p}}^{2}<.01$. Conversely, within the failure condition, followers evaluated the prototypical leader as more effective than the nonprototypical one, $F(1,81)=10.74, p<.01, \eta_{\mathrm{p}}^{2}=.12$. As hypothesized, group prototypicality of the leader "protected" the leader against lower evaluations of leadership effectiveness within the failure condition. In addition, there was no difference in perceptions of leadership effectiveness between a failing and a succeeding leader within the prototypical leader condition, $F(1,81)=2.80, p=.10$, $\eta_{\mathrm{p}}^{2}=.03$. However, participants evaluated the successful/non-prototypical leader as more effective than the failing/non-prototypical leader, $F(1,81)=24.69, p<.01, \eta_{\mathrm{p}}^{2}=.23$.

3.1.2.4. Mediation analyses. We predicted that trust in leadership should be a mediator of the effects of leader group prototypicality on perceived leadership effectiveness within the failure condition. More specifically, we hypothesized that followers would evaluate a failing prototypical leader as more effective than a failing non-prototypical leader, because the prototypical leader is trusted more. To test this prediction we conducted a multiple regression analysis (Baron \& Kenny, 1986) within the failure condition (Fig. 2). The first regression analysis tested whether manipulated leader group prototypicality predicted perceived leadership effectiveness within the failure condition. The second regression analysis examined whether manipulated leader group prototypicality predicted trust in leadership within the failure condition. Finally, the third regression tested the joint influence of leader group prototypicality and trust in leadership on perceived leadership effectiveness within the failure condition. The last analysis tested whether trust in leadership related to leadership effectiveness over and above the effects manipulated leader group prototypicality. Further, in this step the effects of manipulated leader group prototypicality on leadership effectiveness should be weaker than in the first regression.

Leader group prototypicality significantly predicted leadership effectiveness in the first regression analysis, $F(1,34)=9.07$, $p<.01, R^{2}=.21$, and trust in leadership in the second regression analysis, $F(1,34)=6.70, p=.01, R^{2}=.17$. Finally, the last regression analysis predicting leadership effectiveness by leader group prototypicality and trust in leadership yielded a significant effect of trust in leadership, $F(1,33)=18.57, p<.01, R_{\text {change }}^{2}=.28$, and a non-significant effect of leader group prototypicality, $F(1$, $33)=2.69, p=.11, R_{\text {change }}^{2}=.04$. In addition, the results of a Sobel test indicated that trust in leadership significantly reduced the effect of leader group prototypicality, $z=2.22, p=.03$. Thus, this analysis supported our mediation hypothesis. The mediation analysis within the success condition did not yield a mediation effect given that leader group prototypicality failed to predict perceived leadership effectiveness (cf. Baron \& Kenny, 1986).

\subsubsection{Discussion}

Overall, the results of Study 1 supported our hypotheses and were in line with the social identity analysis of organizational leadership (cf. Haslam, 2001; Hogg, 2001; Hogg \& van Knippenberg, 2003). Followers evaluated non-prototypical and prototypical leaders as being similarly effective after the leader succeeded in a performance goal. In contrast, followers evaluated a group

\footnotetext{
${ }^{3}$ We conducted also a 2 (leader prototypicality) $\times 2$ (leader performance) $\times 2$ (participants status: followers vs. non-followers) between-subject ANOVA on leadership effectiveness (including the followers and non-followers, $N=137$ ). The analysis yielded a main effect of leader performance, $F(1,136)=6.43, p=.01$, $\eta_{\mathrm{p}}^{2}=.05$, a significant two-way interaction between leader performance and membership status of leader, $F(1,136)=8.72, p<.01, \eta_{\mathrm{p}}^{2}=.06$, and a significant three-way interaction, $F(1,136)=4.75, p=.03, \eta_{\mathrm{p}}^{2}=.03$. Simple interaction analyses indicated a non-significant leader prototypicality by leader performance interaction within the non-follower condition, $F(1,136)=1.41, p=.24, \eta_{\mathrm{p}}^{2}=.01$, and a significant interaction within the follower condition, $F(1,136)=3.92$, $p<.05, \eta_{\mathrm{p}}^{2}=.03$. Thus, the information about leader group prototypicality and leader performance did only impact on followers, but not on non-followers.
} 


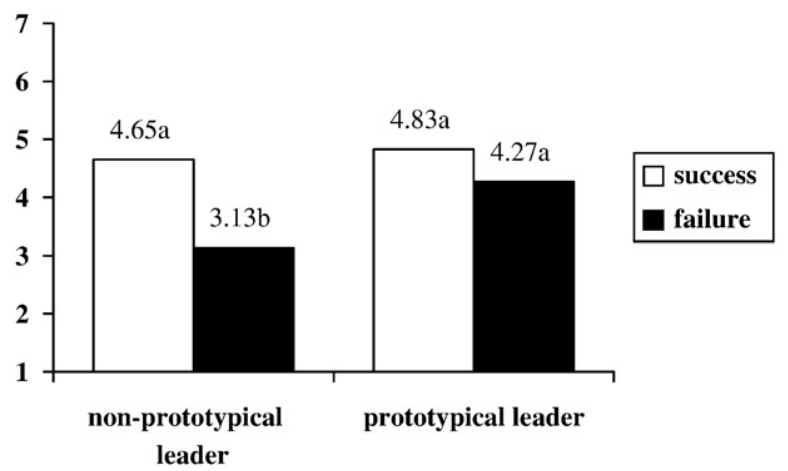

Fig. 1. Leadership effectiveness as a function of leader group prototypicality and leader performance (Study 1). Means with the same subscript do not differ significantly at $p<.05$.

prototypical leader as more effective than a non-prototypical one after the leader failed to reach a performance goal. As hypothesized, this latter effect was mediated by the greater trust in leadership given to a more prototypical leader.

The results also support the "romance of leadership" theory (Meindl et al., 1985), because evaluations of leadership effectiveness were influenced by performance information. In contrast to the research on the romance of leadership, we did not manipulate performance information of the team or organization. Rather, we more directly manipulated performance information related to a leader's action on behalf of the group. In our view, such a manipulation provides a more conservative test of our hypotheses related to the social identity analysis of leadership as it increases the likelihood that followers link the leader to the performance information given. Note, however, that the descriptions of the leader (as used in the scenarios) did not directly indicate that the leader was responsible for the performance. Given this fact, the most important finding is that followers evaluated a prototypical leader as more effective than a non-prototypical leader after failure because this leader received more trust in leadership. Thus, even under this more direct manipulation of performance information, perceptions of leadership effectiveness varied depending on leader prototypicality.

Although we confirmed our hypotheses in a natural setting, we only used hypothetical scenarios to manipulate the independent variables. This certainly limits the generalizability of our results. We used this kind of paradigm because it allowed us to conduct an experimental study outside the laboratory with natural groups. In addition, previous research on leadership has shown that scenario experiments can yield the same results as laboratory and field studies (De Cremer \& van Knippenberg, 2002, 2004; De Cremer, van Knippenberg, van Knippenberg, Mullenders, \& Stinglhamber, 2005; van Knippenberg \& van Knippenberg, 2005). Another possible limitation is that we manipulated leader group prototypicality based on certain characteristics of the leader. Followers not only evaluate the leader based on the perceived characteristics but also based on the leader's behavior (Epitropaki \& Martin, 2004; Haslam et al., 2001; van Knippenberg \& Hogg, 2003). Note, however, that our definition of group prototypicality is about the characteristics and not the behaviors of the leader. Therefore, we deliberately manipulated these characteristics and not leader behaviors. We discuss the issue of leader behavior and leader characteristics in more detail in our general discussion.

Having said this, Study 2 and Study 3 aimed to replicate and extend these findings with a cross-sectional field study and a controlled laboratory experiment.

\subsection{Study 2}

To increase the validity of the results found in Study 1, we aimed to replicate the main findings using cross-sectional data collected in a field context. We used a representative sample of operational employees of a Dutch police organization (support staff

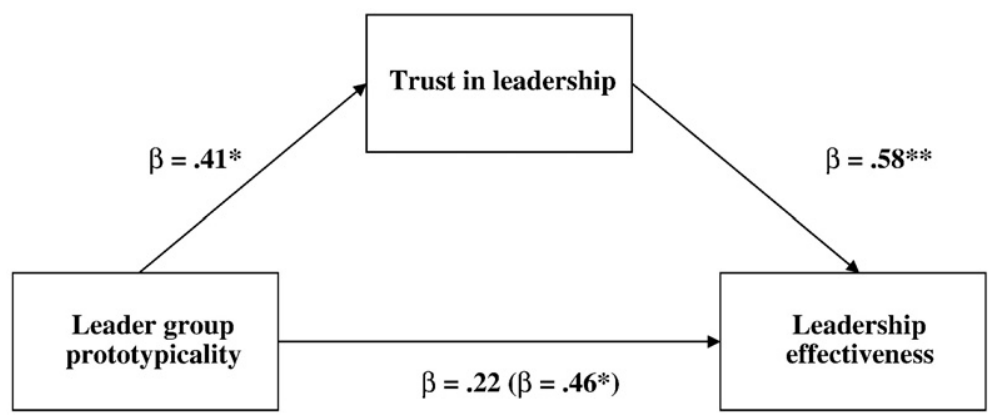

Fig. 2. Mediation analysis of trust in leadership within failure condition using multiple regression analysis (Study 1). 
Table 2

Means, standard deviations, Cronbach's alpha (in correlation matrix diagonal) and correlations of the leader prototypicality, leader performance, and leadership effectiveness in Study 2.

\begin{tabular}{lllll}
\hline & $M$ & $S D$ & $(1)$ & $(2)$ \\
\hline (1) Leader prototypicality & 4.82 & 1.19 & $(.87)$ & $.68^{* *}$ \\
(2) Leader performance & 4.98 & 1.26 & $.72^{* *}$ & - \\
(3) Leadership effectiveness & 4.26 & 1.21 & $.68^{* *}$ & $(.94)$ \\
\hline$* * p<.001$. & & & \\
\hline
\end{tabular}

did not participate in the study). The focus of this survey was not directly on our research question (i.e., the focus of this survey was on diversity in the workforce and organizational communication climate). Therefore, included measures only allowed us to test the effectiveness hypothesis - using measures of leader group prototypicality and leader performance as independent variables and leadership effectiveness as a dependent variable.

\subsubsection{Method}

3.2.1.1. Participants and context. Two hundred ten employees of a Dutch police organization voluntarily participated in this study (gender: 61 females, 142 male, 7 missing values; age: 40 aged under 25 years, 56 aged between 26-35 years, 62 aged between 3645 years; 43 aged between $46-55$ years, 1 aged older than 56 years, 8 missing values).

The surveyed Dutch police organization covers a district in a major city in the Netherlands. This district is split up in six different quarters that all have a leader, who are responsible for all actions happening in their specific quarter and are the focus in the current study. Only employees who conduct operational work were approached to fill out the survey. The total number of employees in focus was 442 employees. The response rate was $48 \%$. The sample was representative for the workforce in terms of age and gender distribution.

3.2.1.2. Procedure. The quarter leaders invited the operational employees of the Dutch police organization to participate in the study by means of e-mail. In this e-mail, the survey was announced, employees were informed about the nature and the general goal of the survey, were guaranteed anonymity, and informed about the specifically placed boxes that collected the filled out questionnaires. The distribution of the questionnaires proceeded by placing hard copy questionnaires in employees' personal mailboxes. After two weeks, a reminder - including a printable version of the questionnaire - was mailed electronically to all operational employees. This made sure that all operational employees had received the questionnaire and could participate in the survey. After six weeks, the survey was stopped.

3.2.1.3. Measures. As indicated above, we were able to add some measures related to the present research question in this survey. We list only the measures important for our research question. These measures were placed in different parts of the questionnaire. The complete questionnaire can be obtained from the third author. If not otherwise indicated, all items used scales ranging from 1 (totally disagree) to 7 (totally agree). Employees had to fill out a 3-item scale measuring perceived group prototypicality of the leader (e.g., "This team leader represents what is characteristic about the team") adapted from Platow \& van Knippenberg (2001). The scale was reliable and the average score served as a measure of leader group prototypicality. Next, a one-item measure asked the employees to indicate to what extent the leader was objectively seen as successful in the fulfilling of tasks and responsibilities in the past couple of months. This item served as our leader performance measure. Finally, employees had to fill out a 5 -item scale adapted from van Knippenberg \& van Knippenberg (2005) measuring perceived leadership effectiveness (e.g., "This team leader is a good leader"; "This team leader is very effective"; "This team leader leads the team in a way which motivates the team members"). We used the average score of leadership effectiveness in our analysis (see Table 2 for means, standard deviations, and correlations of all measures).

\subsubsection{Results}

Three employees did not fill out all of our independent and dependent variables. Therefore, we conducted the analyses with the remaining 207 participants. Furthermore, the independent and dependent variables were strongly correlated which might imply problems related to collinearity. Therefore, we computed different statistics to test whether collinearity was a problem for the statistical test used in this study. Tolerance scores were all above .46, and thus much higher than the usually cut-off score of .10 (Cohen, Cohen, West, \& Aiken, 2003). Also the condition number indices were all below 6, which is much lower than the suggested cut-off point of 15 . Thus, collinearity represented no problem for our analyses.

We conducted a hierarchical regression analysis on the measure of leadership effectiveness. In the first step, we included the dummy-coded district information. This variable served as a covariate in our analyses ${ }^{4}$. In the next step, we included the independent variables: perceived leader prototypicality and perceived leader performance (both centralized). Finally, in the third step we included the interaction of the independent variables. The first step explained a significant proportion of the variance, $F(5$, $201)=11.92, p<.001, R^{2}=.23$. Thus, the absolute values of leadership effectiveness ratings differed between the district leaders.

\footnotetext{
${ }^{4}$ In preliminary analyses, we followed recent statistical recommendations (Yzerbyt, Muller, \& Judd, 2004) and included the interaction of the covariate and the independent variables in the regression analyses to test possible confounds. These interactions were non-significant. In addition, the three-way interaction between the independent variables and the covariate was also non-significant. We, therefore, report the analyses without these interaction terms.
} 
The second step explained an additional significant proportion of the variance, $F(2,199)=168.79, p<.001, R^{2}=.49$. Both leader prototypicality, $b=.38$, SE $b=.06, t(198)=6.88, p<.001$, and leader performance, $b=.44, \operatorname{SE} b=.05, t(198)=8.40, p<.001$, were significantly related to leadership effectiveness perceptions. Thus, the more prototypical the leader was perceived, the more effective the leader was evaluated; and the more employees perceived the leader to be successful, the more they evaluated the leader as effective. Finally, the third step also explained a significant additional proportion of the variance, $F(1,198)=4.15, p=.04$, $R^{2}=.06, b=-.05, \mathrm{SE} b=.02$. Following Aiken \& West (1991), we determined the regression slopes for more successful and less successful leader performance separately (i.e., one standard deviation above and below the mean value of leader performance). As predicted, leader prototypicality yielded a stronger positive relationship to leadership effectiveness evaluations under a less successful performance perception $(\beta=.41, p<.001)$ than under a more successful performance perception $(\beta=.29, p<.001)$. Thus, this finding is in line with our effectiveness hypothesis.

\subsubsection{Discussion}

Study 2 confirmed our effectiveness hypothesis in a cross-sectional field study. Leader group prototypicality and leadership effectiveness had a stronger positive relationship the less successful the leader was perceived to be during the last couple of months. Thus, the results of Study 2 replicated the findings of Study 1 in a cross-sectional field study.

The study has, however, several weaknesses, which should be mentioned. First, the correlations between the variables are relatively strong (see Table 2). This might indicate problems related to mono-method bias in our study. The common method variance created by the mono-method bias is likely to increase correlations between the variables in focus (Podsakoff, MacKenzie, Lee \& Podsakoff, 2003). Therefore, the relatively high correlations between the constructs should be interpreted in the light of this bias. However, our focus was the interaction of leader group prototypicality and leader performance on the measure of leadership effectiveness. The high correlations between the variables make it less likely to find such an interaction effect (McClelland \& Judd, 1993) and common method variance cannot explain or artificially create interactions (Evans, 1985).

A second limitation was the measurement in this study. Because the focus of this study was originally not directly linked to our research question, we had to rely on a one item measure of leader performance. In addition, this study does not include a measure of trust in leadership. Therefore, we could not test for our mediation hypothesis. Finally, cross-sectional surveys do not allow conclusions about causality. We conducted another study, to provide another test of causality and to address the mono-method/mono-source problem.

\subsection{Study 3}

The goal of Study 3 was threefold. First, we aimed to replicate our results in a controlled laboratory context. Therefore, participants were led to believe that they engaged as a four-person group in a computer-mediated task supervised by a leader. In effect this meant that the presence of a leader was simulated via the computer set-up, and participants proceeded through the experiment individually. The study design allowed us to give bogus feedback about the leader's group prototypicality and the leader's performance. Second, we wanted to provide further evidence for our mediation hypothesis. Thus, we aimed to replicate the findings of Study 1 within a different paradigm. Finally, we also looked at how far the performance information changes follower perceptions regarding leadership group prototypicality, to explore whether leaders may gain or lose group prototypicality in the eyes of their followers as a function of their association with success or failure.

\subsubsection{Method}

3.3.1.1. Participants and design. Ninety-eight economics and business administration students (26 females, 72 males; 57 employed, 41 unemployed) participated in this study. All students were Dutch and were studying at an undergraduate level. The age of the participants varied between 17 and 27 years $(M=18.80, \mathrm{SD}=1.35)$. The study used a two factorial between-subjects design manipulating leader group prototypicality (prototypical vs. non-prototypical) and leader performance (success vs. failure). All participants were randomly assigned to one of the conditions. The study was the first study of a set of studies, all of which were unrelated to the current study. Participants received 10 euro for their participation in all studies.

3.3.1.2. Procedure. Participants arrived at the lab and were placed in separate computer cubicles. All instructions were given via computer. The study was introduced as a team game study and participants were informed that they would have to work in virtual teams of four players connected through a network system. Actually, all participants worked individually and all computer interaction was pre-programmed. Participants received the information that the game they were going to play had been adapted from an assessment centre and had different realistic attributes of a natural team context, like a team structure (i.e., leader and followers) and an incentive for good team performance. Next, participants had to fill out a short questionnaire consisting of 12 items, which were later used for the prototypicality manipulation (adapted from van Knippenberg \& van Knippenberg, 2005). Participants were led to believe that the questionnaire measured perception styles, and it would ostensibly be used to decide which of the team players would be assigned the leader position. Subsequently, participants received the information that if their team performed better than the average of all participating teams, they would take part in a 100 euro price draw.

Afterwards participants received bogus feedback about the perception style test, which served as the leader prototypicality manipulation. Half of the participants received the information that the person who had most in common with the other team members and who was most representative for the team would be chosen (prototypical leader). The other half was informed that the 
member who was least similar to the others, and who was least representative for the team, would be chosen (non-prototypical leader). In all conditions the participants were placed in the follower role. Subsequently, we measured perceived group prototypicality of the leader (see measures section).

In order to heighten participants' sense of team interaction, an e-mail system was introduced, which was said to be used during the team game. In this part of the experiment, participants could test this system by writing one e-mail to the other participants and by reading the pre-arranged e-mails of the other (bogus) team members. After writing one e-mail and having read all other e-mails, the participants could continue the experiment.

Next, it was said that the group would start with an amount of 200 points and the leader had already decided to take part in a negotiation task in which the leader could earn 50 additional points. Participants had to wait some seconds and then got feedback on the performance of the leader. Half of the participants were informed that the leader had succeeded in the negotiation task (success condition). The other half of the participants were informed that the leader failed to secure additional points in the negotiation task (failure condition). Subsequently, dependent variables and manipulation checks followed. After finishing, participants were thoroughly debriefed and all participants took part in a prize draw of four times 25 euro (as was formerly promised).

3.3.1.3. Measures. If not otherwise indicated, all items used scales ranging from 1 (totally disagree) to 7 (totally agree). Participants indicated on a 3-item scale measuring perceived group prototypicality of the leader (e.g., "This team leader represents what is characteristic about the team.") adapted from Platow \& van Knippenberg (2001) directly after the leader prototypicality manipulation. The scale was reliable, and the average score served as a manipulation check of leader group prototypicality. Furthermore, participants had to answer the same two trust items as used in Study 1. The items were averaged to one measure of trust in leadership.

All other measures followed after the performance manipulation. First, participants were requested to fill out a 6-item scale adapted from van Knippenberg and van Knippenberg (2005) measuring perceived leadership effectiveness (e.g., "This team leader is a good leader"; "This team leader is very effective"). We used the average score of these items as a measure of perceived leadership effectiveness. Furthermore, we again measured perceived leader group prototypicality using the same items as before the performance manipulations (see Table 3 for means, standard deviations, and correlations of all measures).

Next, participants indicated whether their team leader had succeeded or failed in the negotiation task (i.e., a dichotomous choice). This item served as manipulation check of performance. All participants indicated the intended outcome on the performance manipulation check. Hence, this manipulation was successful. Finally, participants filled out demographic questions regarding their gender, age, and employment status. Preliminary analyses indicated that these factors did not influence our research results.

\subsubsection{Pilot study}

The measures of perceived leader group prototypicality, trust in leadership, and perceived leadership effectiveness may raise questions about potential overlap. For theoretical reasons, we measured prototypicality and trust before and leadership effectiveness after the performance manipulation in Study 3. This means that Study 3 is less suited to explore the dimensionality of these measures. Therefore, to guarantee that these measures do indeed tap related but different constructs, we conducted a pilot study with undergraduate Dutch business administration students $(N=159 ; 113$ male; age $M=19.58, S D=1.67)$. Here, we just presented a short description of a leader followed by exactly the same items used in this study. The study was part of a set of unrelated studies. A principal component analysis with varimax rotation over all 11 items yielded a three-factor solution explaining $82.45 \%$ of the variance. The factor structure resembled the items we used to measure the different constructs. The first factor represented perceived leadership effectiveness including all 6 items (factor loadings varying from .72 to .91; cross loadings $<.29$ ). The second factor represented trust in leadership (factor loadings varying from .90 to .93; cross loadings <.34). The last factor represented leader group prototypicality (factor loadings varying from .80 to .83 ; cross loadings $<.37$ ).

\subsubsection{Results}

3.3.3.1. Leader group prototypicality. In order to test whether the manipulation of prototypicality had the expected effect on perceived prototypicality, an independent samples $t$-test was performed. The analysis yielded a significant effect of the leader group prototypicality manipulation, $t(96)=10.30, p<.001$. The prototypical leader was perceived as more prototypical $(M=4.82$, $\mathrm{SD}=.86)$ than the non-prototypical leader $(M=2.75, \mathrm{SD}=1.10)$, as was intended by the manipulation.

Table 3

Means, standard deviations, Cronbach's alpha (in correlation matrix diagonal) and correlations of the manipulation checks of leader prototypicality (at measurement point 1 and 2), trust in leadership, and leadership effectiveness and in Study 3.

\begin{tabular}{|c|c|c|c|c|c|c|}
\hline & M & $S D$ & (1) & (2) & (3) & $(4)$ \\
\hline (1) Leader prototypicality (measurement point 1 ) & 3.77 & 1.43 & $(.89)$ & & & \\
\hline (2) Trust in leadership & 4.63 & 1.04 & $-.03(.22)$ & $(.66)$ & & \\
\hline (3) Leadership effectiveness & 4.39 & 1.21 & $-.05(.06)$ & $.27 * *(.25)$ & $(.89)$ & \\
\hline (4) Leader prototypicality (measurement point 2 ) & 4.26 & 1.21 & $.53^{* * *}(.72)$ & $.12(.33)$ & $.31 * *(.45)$ & $(.94)$ \\
\hline
\end{tabular}

$* p<.05 * * p<.01 * * * p<.001$.

The correlations not within brackets are partial correlations which have the effect of our manipulations and their interaction removed, whereas the correlations within brackets represent the zero-order correlations. 


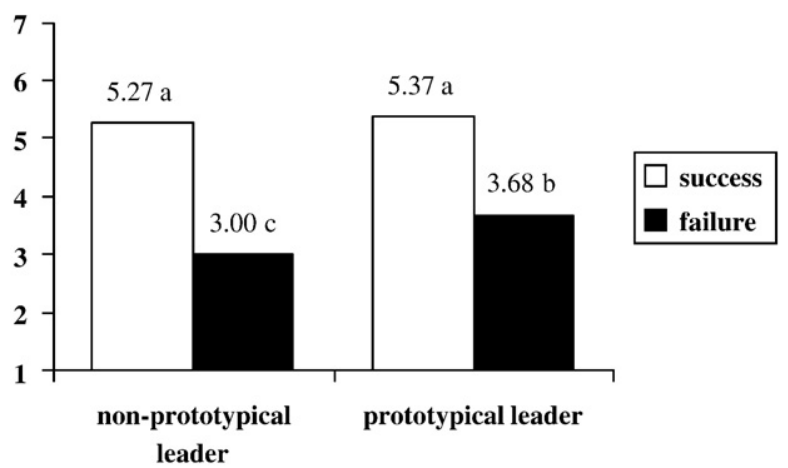

Fig. 3. Leadership effectiveness as a function of leader group prototypicality and leader performance (Study 3 ). Means with the same subscript do not differ significantly at $p<.05$.

3.3.3.2. Trust in leadership. An independent sample $t$-test on trust in leadership yielded a significant effect of the leader group prototypicality manipulation, $t(96)=3.57, p=.001$. In line with our hypothesis, the participants had more trust in the prototypical leader $(M=4.99, \mathrm{SD}=.84)$ than in the non-prototypical leader $(M=4.28, \mathrm{SD}=1.10)$.

3.3.3.3. Leadership effectiveness. To test our effectiveness hypothesis, a 2 (leader group prototypicality) $\times 2$ (leader performance) between-subjects ANOVA was performed on perceived leadership effectiveness. The analysis yielded a main effect of leader group prototypicality, $F(1,94)=10.17, p<.01, \eta_{\mathrm{p}}^{2}=.10$, and a significant main effect of leader performance, $F(1,94)=258.98, p<.01$, $\eta_{\mathrm{p}}^{2}=.73$. These main effects were qualified by the two-way interaction, $F(1,94)=5.54, p=.02, \eta_{\mathrm{p}}^{2}=.06$. The pattern of results (see Fig. 2) again supports our effectiveness hypothesis. Additional simple main effect analyses within the success condition yielded no significant effect of leader group prototypicality on perception of leadership effectiveness, $F(1,94)=.37, p=.54, \eta_{\mathrm{p}}^{2}<.01$. Conversely, within the failure condition, followers evaluated a prototypical leader as more effective than a non-prototypical leader, $F(1,94)=14.46, p<.01, \eta_{\mathrm{p}}^{2}=.13$. As hypothesized, group prototypicality of the leader "protected" the leader against lower evaluations of leadership effectiveness within the failure condition. In addition, there were significant differences in leader endorsement between a failing and a succeeding leader within the prototypical leader condition, $F(1,94)=92.24, p<.01, \eta_{\mathrm{p}}^{2}=.50$, and within the non-prototypical leader condition, $F(1,94)=174.17, p<.01, \eta_{\mathrm{p}}^{2}=.65$ (Fig. 3).

3.3.3.4. Mediation analyses of trust in leadership. We again tested for the mediation of trust in leadership within the failure condition (see Study 1 for a description of the statistical procedure). Leader group prototypicality significantly predicted leadership effectiveness in the first regression analysis, $F(1,44)=16.51, p<.01, R^{2}=.27$, and trust in leadership in the second regression analysis, $F(1,44)=10.32$, $p=.01, R^{2}=.19$. Finally, the last regression predicting leadership effectiveness by leader group prototypicality and trust in leadership yielded a significant effect of trust in leadership, $F(1,43)=10.95, p<.01, R_{\text {change }}^{2}=.20$, and a significant effect of leader group prototypicality, $F(1,43)=6.80, p=.01, R_{\text {change }}^{2}=.14$. A Sobel test indicated that trust in leadership significantly reduced the effect of leader group prototypicality, $z=2.30, p=.02$. Thus, this analysis indicated a partial mediation effect and, hence, supported our mediation hypothesis, although it also suggested that other factors than trust in leadership may also play a role in mediating the observed effect. The mediation analysis within the success condition did not yield a mediation effect given that leader group prototypicality did not significantly predict perceived leadership effectiveness (cf. Baron \& Kenny, 1986) (Fig. 4).

3.3.3.5. Changes in leader group prototypicality. To look at the changes of perceived leader group prototypicality, we conducted a 2 (leader group prototypicality) $\times 2$ (leader performance) $\times 2$ (measurement point) ANOVA (see Table 4 for means and standard

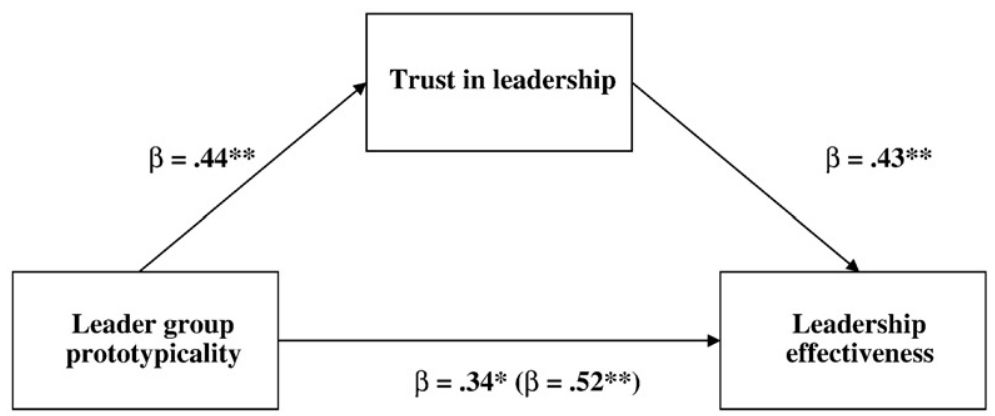

Fig. 4. Mediation analysis of trust in leadership within the failure condition using multiple regression analysis (Study 3). 
Table 4

Means and standard deviations of leader group prototypicality (measured) as a function of leader performance, leader prototypicality, and measurement point (Study 3).

\begin{tabular}{|c|c|c|c|}
\hline \multirow[t]{2}{*}{ Performance } & \multirow[t]{2}{*}{ Leader prototypicality } & \multicolumn{2}{|l|}{ Measurement point } \\
\hline & & Before performance manipulation & After performance manipulation \\
\hline \multirow[t]{6}{*}{ Success } & Prototypical & & \\
\hline & $M$ & 4.78 & 5.00 \\
\hline & $S D$ & .61 & .70 \\
\hline & Non-prototypical & & \\
\hline & $M$ & 2.64 & 3.30 \\
\hline & $S D$ & .90 & 1.27 \\
\hline \multirow[t]{5}{*}{ Failure } & Prototypical & & \\
\hline & $M$ & 4.86 & 4.57 \\
\hline & $S D$ & 1.10 & .84 \\
\hline & Non-prototypical & & \\
\hline & $M$ & 2.88 & 2.43 \\
\hline
\end{tabular}

deviations). The last factor was within subjects. The analysis yielded a significant main effect of leader group prototypicality, $F(1$, $94)=127.39, p<.001, \eta_{\mathrm{p}}^{2}=.58$. Group prototypical leaders were generally perceived as more prototypical $(M=4.81, \mathrm{SD}=.83)$ compared to non-prototypical group leaders $(M=2.84, \mathrm{SD}=1.16)$. In addition, the analysis yielded a significant measurement point by performance interaction, $F(1,94)=19.21, p<.001, \eta_{\mathrm{p}}^{2}=.17$. Simple effect analyses indicated that success increased perceived leader group prototypicality, $F(1,94)=13.20, p<.001, \eta_{\mathrm{p}}^{2}=.12$ (before: $M=3.71, \mathrm{SD}=1.32 ;$ after: $M=4.19, \mathrm{SD}=1.30$ ), whereas failure decreased perceived leader group prototypicality, $F(1,94)=6.76, p=.011, \eta_{\mathrm{p}}^{2}=.07$ (before: $M=3.83$, SD $=1.56$; after: $M=3.46, \mathrm{SD}=1.41$ ).

The analysis also revealed a marginal significant three-way interaction, $F(1,94)=3.12, p=.08, \eta_{\mathrm{p}}^{2}=.03$. Consequently, we conducted additional simple interaction analyses within the performance conditions. The analysis yielded a marginal significant measurement point by leader group prototypicality interaction within the success condition, $F(1,50)=3.36, p=.07, \eta_{\mathrm{p}}^{2}=.06$, but not in the failure condition, $F(1,44)=.38, p=.54, \eta_{\mathrm{p}}^{2}=.01$. Further simple effect analyses within the success/leader prototypicality conditions indicated that non-prototypical group leaders received stronger perceptions of prototypicality after the success feedback, $F$ $(1,50)=13.46, p<.001, \eta_{\mathrm{p}}^{2}=.21$, whereas the level for group prototypical leaders did not change significantly, $F(1,50)=1.16, p=.29$, $\eta_{\mathrm{p}}^{2}=.02$. However, it should be noted that group prototypical leaders were still perceived as more prototypical than non-prototypical leader after both a success and a failure feedback (see Table 4).

\subsubsection{Discussion}

The results of Study 3 replicated the findings of Study 1 and 2 under controlled laboratory conditions. Leader group prototypicality and performance information interacted again in the prediction of followers' evaluations of leadership effectiveness. Whereas followers evaluated prototypical and non-prototypical leaders as being similarly effective after success information, they evaluated a prototypical leader as being more effective than a non-prototypical leader after failure (effectiveness hypothesis). Again, this latter effect was (albeit partly) explained by the greater trust in leadership given to the prototypical leader. Furthermore, we found a strong main effect of the performance manipulation replicating earlier studies on performance information and leader evaluations (Lord et al., 1978; Meindl et al., 1985; Phillips \& Lord, 1981; Rush et al., 1977).

In addition to the former two studies, we found evidence for changes in perceived leader prototypicality after performance feedback. Both a non-prototypical and a prototypical leader gained or lost in perceived group prototypicality after performance information. This indicates the dynamic aspects of group prototypicality (cf. Oakes, Haslam, \& Turner, 1998). The findings also suggest that non-prototypical leaders might gain more in prototypicality perceptions after success than prototypical leaders. However, these effects have to be interpreted with caution for two reasons: (1) the effects were only marginally significant, and (2) the effects of the prototypical leader might be influenced by a ceiling effect (i.e., they could not gain as much in prototypicality as the non-prototypical leaders). Nevertheless, the important message is that non-prototypical group leaders can increase their standing within the team (in terms of group prototypicality) through successful performance.

Similar to Study 1, the performance information was related to a leader's task on behalf of the group. Compared to studies on the romance of leadership, such a manipulation would implicate a much stronger attribution of success and failure to the leader. The results, however, indicate that characteristics of the leader as a group member (i.e., leader group prototypicality) influence effectiveness evaluations of the leader after failure information - which is in line with the social identity analysis of leadership.

Compared to the results of Study 1, this study also yielded some differences, which deserve attention. First, a prototypical leader was still less endorsed after task failure than after task success. This might mainly reflect a stronger importance of the task performance in the laboratory study than in the scenario study because the performance information in the scenario study was only an imaginary situation compared to a real incentive provided in the laboratory study. However, the important (and predicted) finding is the interaction of leader group prototypicality and performance information on leadership effectiveness. Second, trust in leadership explained only partially the effects of leader group prototypicality on leadership effectiveness within the failure 
condition. On the one hand, this implies that trust in leadership is the mediating variable (supporting our mediation hypothesis). On the other hand, this suggests that other variables may mediate these effects as well.

The laboratory may seem a somewhat artificial setting to study the role of leader group prototypicality, given the lack of interaction between leader and followers and the ad hoc nature of the group and the leadership relation. The key point here, however, is that the effects of leader group prototypicality are contingent first and foremost on follower self-categorization as a member of the group and on follower perceptions that the leader is prototypical of the group. Theoretically, neither this selfdefinition nor this leadership perception is dependent on interaction with the leader or on interaction within the group (cf. Tajfel, 1978; Tajfel \& Turner, 1986; Turner, 1985). Indeed, there is an abundance of evidence that even in such 'minimal group' laboratory settings, individuals do see themselves as a member of their group (i.e., identify with the group) and respond to others on the basis of their group membership (for more elaborate discussions of the use of these kind of minimal group set-ups to study social identity processes, see Brewer, 1979; Hewstone, Rubin, \& Willis, 2002; Tajfel, 1982). The study of leader group prototypicality is rooted in this research tradition of studying social identity processes in minimal group situations (e.g., Hains et al., 1997; Platow \& van Knippenberg, 2001; van Knippenberg, van Knippenberg, \& van Dijk, 2000). Testifying to the generalizability of such laboratory findings to the field, laboratory experiments of leader group prototypicality have consistently yielded results that are replicated in and commensurate with findings from field studies (Fielding \& Hogg, 1997; Hains et al., 1997; Hogg et al., 1998; van Knippenberg \& van Knippenberg, 2005; for reviews, see van Knippenberg \& Hogg, 2003; van Knippenberg et al., 2004).

The above notwithstanding, an obvious and important question is whether the relationships studied in the present research may not only be observed in a laboratory setting but also in an organizational setting. To address exactly that question, the present research combined different research methodologies to provide both evidence from controlled experiments that can speak to issues of causality and evidence from the field that can speak to issues of generalizability. Both on theoretical grounds, that suggest that the interaction between leader and follower is not a precondition for the proposed relationships to be obtained, and on the basis of research using comparable experimental set-ups in combination with field surveys (De Cremer \& van Knippenberg, 2002, 2004; De Cremer et al., 2005; van Knippenberg \& van Knippenberg, 2005), we expected that the lab and the field would yield similar results. This was exactly what we found.

\section{General discussion}

Leaders have a central position within the group and, therefore, often have to deal with performance outcomes of their group. Most of the empirical evidence suggests that people often use the leadership of a group as an explanatory category for such performance information (Lord et al., 1978; Meindl et al., 1985; Phillips \& Lord, 1981). Thus, a leader often gains endorsement of followers after success and loses follower endorsement after failure. The latter effect may, however, jeopardize the leader's ability to be effective because followers' endorsement forms the basis for effective leadership (cf. Hollander, 1964). This raises the question of whether there are possible moderators of such an effect.

The present research investigated how perceptions of leader group prototypicality and leader performance influence followers' leadership effectiveness evaluations. Based on prior research on the romance of leadership theory (Meindl \& Ehrlich, 1987; Meindl et al., 1985; see also Lord et al., 1978; Lord \& Maher, 1991) and the social identity analysis of leadership (Haslam \& Platow, 2001; Hogg, 2001; Hogg \& van Knippenberg, 2003; van Knippenberg \& Hogg, 2003; Reicher \& Hopkins, 2003), it was predicted that group prototypical leaders, who embody the group identity, would receive higher evaluations of leadership effectiveness than nonprototypical leaders, but only under failure conditions. In addition, we predicted that trust in leadership mediates the effect of leader prototypicality on leadership effectiveness within the failure condition. The results of Study 1 supported both of our hypotheses in an experimental field study using a scenario approach. Study 2 provided support for the effectiveness hypothesis in a cross-sectional field setting. Because of practical restrictions in this study, we could not provide a measure of trust in leadership to test our mediation hypothesis. Finally, Study 3 replicated and extended the findings in a controlled laboratory study. As in Study 1 and 2, a group prototypical (vs. non-prototypical) leader received higher evaluations of leadership effectiveness when failing in a goal (compared to succeeding in a goal). In addition, leader success increased perception of leader group prototypicality and leader failure decreased perceptions of leader group prototypicality over time.

Our research brings together research on leadership effectiveness evaluations after performance feedback and leader group prototypicality. The synthesis of these perspectives enriches our knowledge about the romance of leadership and the processes underlying leader group prototypicality in the prediction of leadership effectiveness. In the following, we discuss the implications of our findings for research on the romance of leadership and the social identity analysis of leadership, the limitations of our study, the perspectives for future research and practical implications.

\subsection{Leader group prototypicality and responses to performance outcomes}

The current findings have important implications for the romance of leadership theory (Meindl \& Ehrlich, 1987; Meindl et al., 1985). Consistent with the social identity analysis of leadership (Haslam, 2001; van Knippenberg \& Hogg, 2003) leader prototypicality influenced the associations of leaders with performance information. To be more precise, a group prototypical leader received higher evaluations of leadership effectiveness after failing to reach a goal than a non-prototypical one. This indicates that perceptions of the leader as a group member matter for leadership evaluations after performance feedback. Haslam and colleagues (2001) showed that group-affirming (vs. group-negating) behavior of the leader moderates the degree to which a crisis (representing failure information) influences leadership evaluations. Our research indicates that not only the behavior of the 
leader, but also the perception of the leader's group prototypicality influences the relationship between performance information and followers' perception of leadership effectiveness. We replicated our findings within three different research paradigms, in field and laboratory settings, and with three different sample populations. Group prototypical leaders as opposed to non-prototypical leaders received more positive evaluations of leadership effectiveness after failure. In other words, a prototypical leader had some "license to fail", whereas a non-prototypical leader did not have such credit.

The present research also provides evidence for an underlying mechanism of the "license to fail" for group prototypical leaders. The findings of Study 1 and 3 indicate that the more trust in leadership given to a prototypical (vs. non-prototypical) group leader mediates the effects of leadership effectiveness after failure information. Although this mediating mechanism has been suggested by recent research on the social identity analysis of leadership (Platow \& van Knippenberg, 2001; van Knippenberg \& Hogg, 2003; van Knippenberg \& van Knippenberg, 2005), it had not yet been tested. Interestingly, this finding is also in line with Hollander's (1964) theory of idiosyncrasy credit - which can be understood as a kind of trust in leadership. However, whereas Hollander assumed that idiosyncrasy can only be earned through behavior of the leader or exchange relationships between leader and followers, the social identity extends this view by predicting and showing in this research that perceptions of the leader in terms of group prototypicality can be the basis of trust in leadership perceptions.

Nevertheless, the findings of Study 3 do indicate that trust in leadership might not be the only mediating mechanism. Different kinds of processes might underlie the effects of leader group prototypicality on leadership effectiveness perception. One such mediating process might be the greater depersonalized attraction a prototypical (vs. non-prototypical) group member receives from other group members (Hogg, Cooper-Shaw, \& Holzworth, 1993). To be more precise, theoretical and empirical work by Hogg and colleagues showed that within a salient intergroup context (i.e., identification with the group is strong), liking of group members is determined by their degree of group prototypicality. Such feelings of liking may not necessarily involve perceptions of trust and may therefore act as an independent mediating process (cf. Hogg \& van Knippenberg, 2003).

Our research focused mainly on follower perceptions of leadership effectiveness after performance information because we aimed to extend the theoretical perspective of the romance of leadership theory. Nevertheless, the findings of Study 3 indicate that not only perceived leadership effectiveness is influenced by perceived group prototypicality of a leader and performance information. Rather, perceived leader group prototypicality itself is shown to change after performance information. Group prototypes are influenced by the social context (Turner et al., 1987). Although there is some debate among social identity scholars in how far group prototypes are responsive to contextual changes (Oakes et al., 1998) or provide stability and are therefore slower to change (Abrams \& Hogg, 2001; Hogg, 2003), there is agreement that group prototypes are dynamic in nature. But the aim of our research was not primarily to show these dynamic aspects of leader prototypicality perceptions. Therefore, Study 1 used a rather fixed conceptualization of leader prototypicality. In contrast, Study 2 then measured perceived leader prototypicality and, thus, did not fix prototypicality perception. Finally, we measured changes in perceived group prototypicality in Study 3. The results indicate that performance information indeed influences leader prototypicality perceptions. Thus, success and failure of a leader can either increase or decrease perceived leader prototypicality. However, it is worth mentioning that the prototypical leader was still perceived as more prototypical than the non-prototypical leader after failure. Thus, this may indicate that, one the one hand, prototypicality is dynamic and influenced by social context changes, and, on the other hand, also has some stability.

Our research focused on one performance goal only. Often leaders and their groups have more than one performance goal and, therefore, receive feedback about their performance in relation to more than one goal. Thus, leaders or their groups may repeatedly fail or succeed on different goals. Given the findings of Study 3, we may predict that such repeated performance feedback can influence followers' perceptions of leader group prototypicality and/or trust in leadership over time. Thus, a prototypical leader who repeatedly fails might be perceived as non-prototypical at one point in time. In a similar vein, a less prototypical leader might be able to improve followers' perception of group prototypicality through repeated success. Study 3 shows the first evidence of such changes in leader group prototypicality perceptions due to performance information. One might question how far the "license to fail" has real world applicability because of these influences of performance on leader group prototypicality. Notice, however, that a failing prototypical leader was still perceived as more prototypical than the succeeding non-prototypical leader. Thus, we assume that either several experiences of failure or success are required to change prototypicality perceptions, or that very dramatic performance feedback is required. In addition, our research indicates that followers still endorse a failing group prototypical leader, and this finding was also established in the field. Knowing that group prototypical leaders keep their 'license to fail' after initial failure is already a very important message from a practical point of view. We discuss the possible consequences of it below.

\subsection{Practical implications}

One premature conclusion from our research might be to assume that group prototypical leaders are better leaders. From the perspective of the leader, being group prototypical can be an advantage, since a prototypical group leader (compared to a nonprototypical one) maintains more follower endorsement after performance failure. As a result, the leader can deal more easily with throwbacks and has less pressure to be a successful leader. Also from an organizational perspective, this can be good news. Research by Lord, Meindl, and others (Lord et al., 1978; Lord \& Maher, 1991; Meindl et al., 1985) point to the fact that performance outcomes are often over-attributed to leaders, although they might not be responsible for these outcomes. It would not be in the interest of an organization to lose a good leader because of this over-attribution of performance outcomes. Leader group prototypicality is able to constrain this effect. In a similar vein, sometimes the performance of a leader might only pay off in the 
long run and not in the short term. To withdraw the trust in the leader, and therefore the basis to be an effective leader, too early, can be a danger for the organization.

However, these positive viewpoints from the perspective of the organization imply, at the same time, a more negative or "dark" side. There is a danger that a group prototypical leader is endorsed even when the leader is the cause of failure. Even when the leader's performance or behaviors jeopardize the whole group or organization, followers might still endorse and trust the leader with potentially detrimental consequences for the group. Therefore, the moderating effect of leader group prototypicality on responses to leader performance should be seen as something that may have positive as well as negative consequences for groups and organizations. Thus, in conclusion, it is important to recognize this double-edged sword of the interactive effects of leader performance and leader group prototypicality on leadership effectiveness.

For management practice, our results may also be relevant in terms of leader promotion decisions. Our research indicates that perceptions of leaders are not only influenced by the actual performance but also by their group prototypicality. Promotion decisions might be biased in this sense. The evaluations of group prototypical (vs. less prototypical) leaders might be less influenced by their prior performance, which, for the reasons outlined above, might be both a good thing and a bad thing.

Finally, the results of Study 3 indicate that leaders can increase their perceived leader prototypicality, which in turn would make them more effective (in terms of influence over followers). More precisely, non-prototypical leaders should show successful performance, because this increases perceptions of group prototypicality. Thus, the ability of newly appointed non-prototypical leaders to mobilize their followers might be increased if the leader initially receives assignments which are likely to end in success. In this way the leader might be able to build up trust in leadership.

\subsection{Leader group prototypicality, leader schemas, and leader behavior}

Based on a social identity analysis of leadership, we developed a theoretical account for leader evaluations after performance information. We acknowledge that other processes might also play an important role in the prediction of leader perceptions. Most closely related seem to be research on theories of implicit leadership and leader categorization theory (Epitropaki \& Martin, 2004; House et al., 1999; Lord \& Emrich, 2001; Offermann et al., 1994). As we already discussed in our introduction, empirical research indicates that group prototypes become more important for the leader evaluation when group membership salience is high, whereas implicit leader schemas become more important reference points of leadership evaluations when group membership salience is low (Hains et al., 1997; Lord \& Hall, 2003). In practice, the salience level of group membership will rarely be so high that individual schema processes are not important at all (and vice versa). Thus, we would predict that leader evaluations are often based on judgments of group prototypicality as well as on judgments based on general implicit leader schemas.

Our research focused on leader group prototypicality as a moderator of the relationship between performance information and perceptions of leadership effectiveness. Based on the social identity perspective on leadership (Hogg \& van Knippenberg, 2003; van Knippenberg \& Hogg, 2003), we defined leader group prototypicality as a cognitive structure, which reflects the essential characteristics of a group (in terms of norms, ideals, history, etc.). In this way, leader prototypicality does not equal leadership behaviors. However, we know from former research that leadership behaviors also form an important part of followers' leadership perceptions. Former research, for instance, indicated that a leader who shows behaviors that affirm the social identity of the group are also more supported than a leader who does not affirm the identity (Haslam et al., 2001). Thus, leader behaviors might have the same effects as leader prototypicality in terms of representing the ideal characteristics of the group (cf. van Knippenberg \& Hogg, 2003). In addition, it might be interesting to test whether the moderating effect of leader group prototypicality still holds if we control for more general leadership behaviors. Former research by Ensari and Murphy (2003) indicated that after controlling for effects of general leadership impressions (cf. Maurer \& Lord, 1991), leader schemas sill explained variance in the prediction of leader charisma. Based on this finding, we would also assume that leader group prototypicality explains additional variance to more general leadership behavior. Support for this reasoning may be found in studies showing interactive effects of leader group prototypicality and leader behavior (Platow \& van Knippenberg, 2001; Platow et al., 2006; van Knippenberg \& van Knippenberg, 2005).

A group prototypical leader might be able to show more unconventional behaviors than non-prototypical behaviors because such leaders receive more trust in leadership. Indeed, former research based on a social identity perspective on leadership showed that follower endorsement of prototypical (vs. less prototypical) leaders is less contingent on leader behaviors that indicates the leader's group-orientation, such as self-sacrificing behavior on behalf of the group (van Knippenberg \& van Knippenberg, 2005), or ingroup-favoring allocation decisions (Platow \& van Knippenberg, 2001). In other words, prototypical leaders can show behaviors that deviate from the norm. These findings are interesting in relation to research on charismatic theories of leadership. Conger \& Kanungo (1987) argued that successful leaders act in more unconventional ways (cf. behavior that deviates from the group norms). Based on our research, we predict that group prototypical leaders might be able to show such unconventional behaviors. Indeed van Knippenberg and Hogg (2003) argue that there is some overlap between charismatic and transformational leadership theories and the social identity analysis of leadership. Leader group prototypicality can be seen as a factor that feeds into attributions of charisma. Recent empirical evidence indeed indicates that more prototypical leaders are perceived as more charismatic (Platow et al., 2006; van Knippenberg \& van Knippenberg, 2005). In sum, the social identity analysis of leadership might also help to better understand the processes underlying charismatic and transformational leadership perceptions (see van Knippenberg \& Hogg, 2003, for an extensive discussion of this point). 


\subsection{Limitations and directions for future research}

Of course, the present study is not without its weaknesses and limitations. Our research focused on followers' perceptions of leadership effectiveness. Our goal was to understand how followers evaluate leaders after performance feedback information because the followers' endorsement of a leader is important for a leader's ability to influence and motivate the followers (Chemers, 2001; Yukl, 2001) and, thus, to also increase performance levels of groups (van Knippenberg \& Hogg, 2003). We do not claim, however, that other processes and variables might be as well influenced by performance information and/ or perceived leader group prototypicality. The findings of Study 3 indicate that leader group prototypicality is influenced by performance information. Other variables like changes in trust in leadership, or perceived charisma of the leader could be influenced by the performance information and leader group prototypicality. Changes in trust in leadership might be interesting in this regard. Given the findings of Study 3 relating to changes in leader prototypicality perceptions, we may assume that trust in leadership will also be influenced by performance information. This process might additionally underlie the effects on perceived leadership effectiveness.

In our research, we used three different paradigms to test our predictions. Each paradigm has certain weaknesses in terms of causality, generalization, or manipulation. We relied on (laboratory) experimental methodologies in Study 1 and 3 . The clear advantage of this approach is that it allows for conclusions regarding causality with high internal validity. However, such an approach is not sufficient to provide external validity. Therefore, we conducted a survey in a field setting in a Study 2 . This crosssectional study provides data with stronger external, but weaker internal validity. Thus, each paradigm can be criticized individually. However, similar to previous leadership studies combining laboratory experiments, scenario experiments, and surveys of leadership in the field (De Cremer et al., 2005; De Cremer \& van Knippenberg, 2002, 2004; van Knippenberg \& van Knippenberg, 2005; also see Dipboye, 1990; Locke, 1986), we could replicate our experimental findings in a field setting. Thus, the strength of our research lies in the overall consistent effects across all three studies. Our theoretical account of these effects provides a parsimonious explanation of the findings in all studies.

However, we also want to point out some exceptions to our findings, which were not replicated across all three studies and therefore might require further research to establish their reliability. First, we were not able to test the mediating role of trust in leadership in our field study. Our findings and conclusions on trust in leadership are solely based on experimental research paradigms. These settings have more demand characteristics than field settings (Judd, Smith, \& Kidder, 1991). Thus, we cannot yet generalize the experimental findings regarding trust in leadership to the field. In addition, our measure of trust in leadership consisted only of two items and might be questioned in terms of its validity. Note, however, that the pilot study of Study 3 indicated that the measure differed from leadership effectiveness evaluations and leader prototypicality perceptions. Nevertheless, future research should test this effect in the field with a more reliable measure. Second, the findings of Study 3 indicated that perceptions of leader prototypicality were influenced by performance information. Thus, although we treated these two variables as independent in our research, this finding suggests that these two variables might be correlated in the field. Indeed, the findings in Study 2 support this assumption. Although it was not the main focus of our research, we think that it is an important avenue to study the longitudinal effects of performance information on prototypicality and trust perceptions.

We applied a social identity analysis of leadership to predict that leader group prototypicality has a moderating effect on the relation between performance information and followers' evaluations of leadership effectiveness. Adapting such a perspective, we would also predict a stronger moderating effect the more followers define themselves in terms of their group membership (i.e., group identification). Group identification has been shown to be a key moderator of the effects of group prototypicality on evaluation of group members, and, therefore, also group leaders (Hains et al., 1997; Hogg, 2001; Platow et al., 2003). Consequently, we argue that the moderating effect of group prototypicality will be more pronounced if followers have a strong degree of group identification. In our studies, participants were either direct followers of the leader's party (Study 1), followers of a district leader (Study 2), or followers of an ostensible team leader (Study 3). Thus, we assumed that our participants had some general degree of identification with their team. Actually, the results of the non-followers in Study 1 (see footnote 3) give some indirect evidence for this assumption because only our follower sample supported our hypotheses but not the non-follower sample. Nevertheless, while this is a prediction that is in line with a social identity analysis of leadership, it still requires direct empirical evidence.

Finally, it is also important to note that in a natural context the group prototypicality of a leader is not just a "given" as it has been in our studies. Rather, leaders actively manage their "image of prototypicality" (Haslam, 2001; Reicher \& Hopkins, 2003; van Knippenberg \& Hogg, 2003). A leader defines the group and its surrounding social context through behaviors and decisions. Thus, leaders define the "identity" of the group, and can be, therefore, described as 'entrepreneurs of identity' (Reicher \& Hopkins, 2003). Research by Reicher and Hopkins provide empirical evidence of such processes in the context of political leadership. Thus, leaders may actively influence their image of being group prototypical. By doing so, leaders can create some "license to fail" in forthcoming tasks if they create an image of being very prototypical for their team or organization. Recently, Lord and Hall (2005) argued that leaders develop their leadership skills over time. They reasoned that mainly leaders in a later developmental stage in terms of leadership skills (i.e., intermediate level and deep structure level) will focus on a collective identity level. Therefore, especially these leaders might be able to be such entrepreneurs of identity. So far, most of this research consists of qualitative case studies and it would be interesting to test these ideas under more controlled laboratory conditions in the future.

\subsection{To conclude}

The performance of leaders often influences the attributions of leader abilities. As a result, the leaders' basis to influence and mobilize followers will be threatened or strengthened by such performance information. Knowing what factors underlie and 
influence this attribution process might help leaders, followers, and organizations to better understand and respond to performance information. The present study hopes to give this area of research new impetus by pointing to the value of an analysis of responses to leader goal achievement in terms of social identity processes.

\section{References}

Abrams, D., \& Hogg, M. A. (2001). Collective identity: Group membership and self-conception. In M. A. Hogg \& R.S. Tindale (Eds.), Blackwell handbook of social psychology: Group processes (pp. 425-460). Oxford, UK: Blackwell.

Aiken, L. S., \& West, S. G. (1991). Multiple regression: Testing and interpreting interactions. Newbury Park, CA: Sage.

Awamleh, R., \& Gardner, W. L. (1999). Perceptions of leader charisma and effectiveness: The effects of vision content, delivery, and organizational performance. Leadership Quarterly, 10, 345-373.

Baron, R. M., \& Kenny, D. A. (1986). The moderator-mediator variable distinction in social psychological research: Conceptual, strategic, and statistical considerations. Journal of Personality and Social Psychology, 51, 1173-1182.

Brewer, M. B. (1979). In-group bias in the minimal intergroup situation: A cognitive-motivational analysis. Psychological Bulletin, 86, $307-324$.

Chemers, M. M. (2001). Leadership effectiveness: An integrative review. In M. A. Hogg \& R.S. Tindale (Eds.), Blackwell handbook of social psychology: Group processes (pp. 376-399). Oxford, UK: Blackwell.

Choi, Y., \& Mai-Dalton, R. R. (1998). On the leadership function of self-sacrifice. Leadership Quarterly, 9, 475-501.

Cohen, J., Cohen, P., West, S. G., \& Aiken, L. S. (2003). Applied multiple regression/correlation analysis fort he behavioral sciences, (3rd ed) Mawah, New Jersey: Lawrence Erlbaum Associates.

Conger, J. A., \& Kanungo, R. N. (1987). Towards a behavioral theory of charismatic leadership in organizational settings. Academy of Management Review, 12, 637-647.

De Cremer, D. (2002). Charismatic leadership and cooperation in social dilemmas: A matter of transforming motives? Journal of Applied Social Psychology, 32, 997-1016.

De Cremer, D., van Knippenberg, B., van Knippenberg, D., Mullenders, D., \& Stinglhamber, F. (2005). Rewarding leadership and fair procedures as determinants of self-esteem. Journal of Applied Psychology, 90, 3-12.

De Cremer, D., \& van Knippenberg, D. (2002). How do leaders promote cooperation? The effects of charisma and procedural fairness. Journal of Applied Psychology, $87,858-866$

De Cremer, D., \& van Knippenberg, D. (2004). Leader self-sacrifice and leadership effectiveness: The moderating role of leader self-confidence. Organizational Behavior and Human Decision Processes, 95, 140-155.

Dipboye, R. L. (1990). Laboratory vs. field research in industrial and organizational psychology. In C. L. Cooper \& I.T. Robertson (Eds.), International review of industrial and organizational psychology, Vol. 5. (pp. 1-34)Chichester, United Kingdom: Wiley.

Dirks, K. T., \& Ferrin, D. L. (2002). Trust in leadership: Meta-analytic findings and implications for research and practice. Journal of Applied Psychology, 87, 611-628.

Duck, J. M., \& Fielding, K. S. (1999). Leaders and subgroups: One of us or one of them? Group Processes and Intergroup Relations, 2, $203-230$.

Ensari, N., \& Murphy, S. E. (2003). Cross-cultural variations in leadership perceptions and attribution of charisma to the leader. Organizational Behavior and Human Decision Processes, 92, 52-66.

Epitropaki, O., \& Martin, R. (2004). Implicit leadership theories in applied settings: Factor structure, generalizability, and stability over time. Journal of Applied Psychology, 89, 293-310.

Evans, M. G. (1985). A Monte Carlo study of the effects of correlated method variance in moderated multiple regression analysis. Organizational Behavior and Human Decision Processes, 36, 305-323.

Fielding, K. S., \& Hogg, M. A. (1997). Social identity, self-categorization, and leadership: A field study of small interactive groups. Group Dynamics: Theory, Research, and Practice, $1,39-51$.

Hains, S. C., Hogg, M. A., \& Duck, J. M. (1997). Self-categorization and leadership: Effects of group prototypicality and leader stereotypicality. Personality and Social Psychology Bulletin, 23, 1087-1100.

Haslam, S. A. (2001). Psychology in organizations: The social identity approach. London: Sage.

Haslam, S. A., \& Platow, M. J. (2001). The link between leadership and followership: How affirming social identity translates vision into action. Personality and Social Psychology Bulletin, 27, 1469-1479.

Haslam, S. A., Platow, M. J., Turner, J. C., Reynolds, K. J., McGarty, C., Oakes, P., et al. (2001). Social identity and the romance of leadership: The importance of being seen to be 'doing it for us'. Group Processes and Intergroup Relations, 4, 191-205.

Hewstone, M., Rubin, M., \& Willis, H. (2002). Intergroup bias. Annual Review of Psychology, 53, 575-604.

Hogg, M. A. (2001). A social identity theory of leadership. Personality and Social Psychology Review, 5, $184-200$.

Hogg, M. A. (2003). Social identity. In M. R. Leary \& J.P. Tangney (Eds.), Handbook of self and identity (pp. 462-479). New York: Guilford.

Hogg, M. A., Cooper-Shaw, L., \& Holzworth, D. W. (1993). Group prototypicality and depersonalized attraction in small interactive groups. Personality and Social Psychology Bulletin, 19, 452-465.

Hogg, M. A., Hains, S. C., \& Mason, I. (1998). Identification and leadership in small groups: Salience, frame of reference, and leader stereotypicality effects on leader evaluations. Journal of Personality and Social Psychology, 75, 1248-1263.

Hogg, M. A., \& van Knippenberg, D. (2003). Social identity and leadership processes in groups. In M. P. Zanna (Ed.), Advances in experimental social psychology, Vol. 35. (pp. 1-52)San Diego, CA: Academic Press.

Hollander, E. P. (1964). Leaders, groups, and influence. New York: Oxford University Press.

Hollander, E. P., \& Offerman, L. R. (1990). Power and leadership in organizations. American Psychologist, 45, 179-189.

House, R. J., \& Aditya, R. N. (1997). The social scientific study of leadership: Quo vadis? Journal of Management, $23,409-473$.

House, R. J., Hanges, P. J., Ruiz-Quantilla, S. A., Dorfan, P. W., Javadin, M., Dickson, M., et al. (1999). Cultural influences on leadership and organizations: Project GLOBE. In W. H. Mobley (Ed.), Advances in global leadership, vol. 1. (pp. 171-233)Stamford, CT: JAI Press.

Judd, C. M., Smith, E. R., \& Kidder, L. H. (1991). Research methods in social relations, (6th ed) Orlando, FL: Holt, Rinehart and Winston.

Locke, E. A. (Ed.). (1986). Generalizing from laboratory to field settings: Research findings from industrial-organizational psychology, organizational behavior, and human resources management Lexington, MA: Heath-Lexington Books.

Lord, R. G., Binning, J. F., Rush, M. C., \& Thomas, J. C. (1978). The effect of performance cues and leader behavior on questionnaire ratings of leadership behavior. Organizational Behavior and Human Performance, 21, 27-39.

Lord, R. G., \& Emrich, C. G. (2001). Thinking outside the box by looking inside the box: Extending the cognitive revolution in leadership research. Leadership Quarterly, 11, 551-579.

Lord, R. G., Foti, R. J., \& DeVader, C. L. (1984). A test of leadership categorization theory: Internal structure, information processing, and leadership perceptions. Organizational Behavior and Human Performance, 34, 343-378.

Lord, R. G., \& Hall, R. (2003). Identity, leadership categorization and leadership schema. In D. van Knippenberg \& M.A. Hogg (Eds.), Leadership and power: Identity processes in groups and organizations (pp. 48-64). London: Sage.

Lord, R. G., \& Hall, R. (2005). Identity, deep structure and the development of leadership skill. Leadership Quarterly, 16, $591-615$.

Lord, R. G., \& Maher, K. (1991). Leadership and Information Processing: Linking Perceptions and Performance. Boston, MA: Unwin Hyman.

Maurer, T. J., \& Lord, R. G. (1991). An exploration of cognitive demands in group interaction as a moderator of information processing variables in perceptions of leadership. Journal of Applied Social Psychology, 21, 821-839. 
Mayer, M. (2004). Europawahl - Grüne holen in Marburg 28,1 Prozent [European elections - Greens get 28,1 per cent]. Oberhessische Presse. Retrieved November 10, 2004, from http://www.op-marburg.de/op/home.news.lokal/article.op.jsp?-marburg.de/op/home.news.lokal/article.op.jsp?id=20040613.436141 McClelland, G. H., \& Judd, C. M. (1993). Statistical difficulties of detecting interactions and moderator effects. Psychological Bulletin, 114, $376-390$.

Meindl, J. R., \& Ehrlich, S. B. (1987). The romance of leadership and the evaluation of organizational performance. Academy of Management Journal, 30 , $91-109$.

Meindl, J. R., Ehrlich, S. B., \& Dukerich, J. M. (1985). The romance of leadership. Administrative Science Quarterly, 30, 78-102.

Oakes, P., Haslam, A., \& Turner, J. C. (1998). The role of prototypicality in group influence and cohesion: Contextual variation in the graded structure of social categories. In S. Worchel, J. F. Morales, D. Páez, \& J. -C. Deschamps (Eds.), Social identity: International perspectives (pp. 75-92). London: Sage.

Offermann, L. R., Kennedy, J. K., Jr., \& Wirtz, P. W. (1994). Implicit leadership theories: Content, structure and generalizability. Leadership Quarterly, 5, 43-58.

Phillips, J. S., \& Lord, R. G. (1981). Causal attributions and perceptions of leadership. Organizational Behavior and Human Behavior, $28,143-163$.

Pierro, A., Cicero, L., Bonaiuto, M., van Knippenberg, D., \& Kruglanski, A. W. (2005). Leader group prototypicality and leadership effectiveness: The moderating role of need for cognitive closure. The Leadership Quarterly, 16, 503-516.

Platow, M. J., Haslam, S. A., Foddy, M., \& Grace, D. M. (2003). Leadership as the outcome of self-categorization processes. In D. van Knippenberg \& M.A. Hogg (Eds.), Leadership and power: Identity processes in groups and organizations (pp. 34-47). London: Sage.

Platow, M. J., Hoar, S., Reid, S. A., Harley, K., \& Morrison, D. (1997). Endorsement of distributively fair and unfair leaders in interpersonal and intergroup situations. European Journal of Social Psychology, 27, 465-494.

Platow, M. J., Reid, S. A., \& Andrew, S. (1998). Leadership endorsement: The role of distributive and procedural behavior in interpersonal and intergroup contexts. Group Processes and Intergroup Relations, 1, 35-47.

Platow, M. J., \& van Knippenberg, D. (2001). A social identity analysis of leadership endorsement: The effects of leader ingroup prototypicality and distributive intergroup fairness. Personality and Social Psychology Bulletin, 27, 1508-1519.

Platow, M. J., van Knippenberg, D., Haslam, S. A., van Knippenberg, B., \& Spears, R. (2006). A special gift we bestow on you for being representative of us: Considering leader charisma from a self-categorization perspective. British Journal of Social Psychology, 45, 303-320.

Podsakoff, P. M., MacKenzie, S. B., Lee, J., \& Podsakoff, N. P. (2003). Common method biases in behavioral research: A critical review of the literature and recommended remedies. Journal of Applied Psychology, 88, 879-903.

Reicher, S., \& Hopkins, N. (2001). Self and Nation. London: Sage.

Reicher, S., \& Hopkins, N. (2003). On the science and art of leadership. In D. van Knippenberg \& M.A. Hogg (Eds.), Leadership and power: Identity processes in groups and organizations (pp. 197-209). London: Sage.

Rosch, E. (1978). Principles of categorization. In E. Rosch \& B.B. Lloyd (Eds.), Cognition and categorization (pp. 27-48). Hillsdale, NJ: Erlbaum.

Rousseau, D. M., Sitkin, S. B., Burt, R. S., \& Camerer, C. (1998). Not so different after all: A cross-discipline view of trust. Academy of Management Review, 23, 393-404.

Rush, M. C., Thomas, J. C., \& Lord, R. G. (1977). Implicit leadership theory: A potential threat to the internal validity of leader behavior questionnaires. Organizational Behavior and Human Performance, 20, 93-110.

Shamir, B. (1992). Attribution of influence and charisma to the leader: The romance of leadership revisited. Journal of Applied Social Psychology, $22,386-407$.

Sherif, M., \& Sherif, C. W. (1964). Reference groups. New York: Harper \& Row.

Tajfel, H. (1978). Differentiation Between Social Groups: Studies in the Social Psychology of Intergroup Relations. New York: Academic Press.

Tajfel, H. (1982). Social psychology of intergroup relations. Annual Review of Psychology, 33, 1-39.

Tajfel, H., \& Turner, J. C. (1986). The social identity theory of intergroup behaviour. In S. Worchel \& W.G. Austin (Eds.), Psychology of intergroup relations (pp. 7-24). Chicago: Nelson-Hall.

Turner, J. C. (1985). Social categorization and the self-concept: A social cognitive theory of group behaviour. In E. J. Lawler (Ed.), Advances in group processes, Vol.2. (pp. 77-122)Greenwich, CT: JAI Press.

Turner, J. C. (1991). Social influence. Milton Keynes, England: Open University Press.

Turner, J. C., Hogg, M. A., Oakes, P. J., Reicher, S. D., \& Wetherell, M. S. (1987). Rediscovering the social group: A self-categorization theory. Oxford, U.K.: Basil Blackwell.

van Knippenberg, B., \& van Knippenberg (2005). Leader self-sacrifice and leadership effectiveness: The moderating role of leader prototypicality. Journal of Applied Psychology, 90, 25-37.

van Knippenberg, D., \& Hogg, M. A. (2003). A social identity model of leadership effectiveness in organizations. In B. M. Staw \& R.M. Kramer (Eds.), Research in organizational behavior, Vol. 25. (pp. 243-295)Amsterdam: Elsevier.

van Knippenberg, D., van Knippenberg, B., De Cremer, D., \& Hogg, M. A. (2004). Leadership, self, and identity: A review and research agenda. Leadership Quarterly, $15,825-856$

van Knippenberg, D., van Knippenberg, B., \& van Dijk, E. (2000). Who takes the lead in risky decision making? Effects of group members' individual riskiness and prototypicality. Organizational Behavior and Human Decision Processes, 83, 213-234.

Yukl, G. (2001). Leadership in organizations, (5th ed.) New York: Prentice Hall.

Yzerbyt, V. Y., Muller, D., \& Judd, C. M. (2004). Adjusting researchers' approach to adjustment: On the use of covariates when testing interactions. Journal of Experimental Social Psychology, 40, 424-431. 